\section{Bacteroides fragilis septicaemia and meningitis in early infancy}

Isolation of Bacteroides sp. by laboratories has occurred with increasing frequency in recent years, and there is a growing awareness of clinical infections caused by these anaerobic Gram-negative bacilli. Meningitis in children, however, has been rare, and has not previously been reported before the age of 6 months. A case of Bacteroides fragilis meningitis in a 7-week-old infant is recorded here; it was secondary to peritonitis and septicaemia which developed in the third week of life.

\section{Case report}

A 16-day-old white male was admitted to hospital with a 2-day history of constipation, refusal of feeds, and vomiting. On the day of admission the vomit was bile-stained. Previous medical history was uneventful. On examination the infant was markedly dehydrated and was vomiting bile. The abdomen was tense, tinkling bowel sounds were heard, and an irreducible right inguinal hernia was present. Abdominal $x$-ray showed appearances of small bowel obstruction.

Rehydration with intravenous dextrose-saline was begun, and a laparotomy performed, during which a small amount of blood from an adult donor was transfused. The findings were of an inguinal hernia containing viable small bowel, although two small perforations had occurred at the level of the constriction ring, causing a faecal peritonitis. The hernial sac was excised, the perforations closed, and peritoneal toilet performed before closing the abdomen.

Five hours after operation the baby became apnoeic, and was noted to have a poor peripheral circulation and cyanosis. Mechanical ventilation became necessary. A Gram-negative bacterial septicaemia was suspected, and treatment with intravenous ampicillin, gentamicin, and hydrocortisone was started after blood cultures had been taken. Further investigations showed a haemoglobin of $17.6 \mathrm{~g} / \mathrm{dl}$, a total white cell count of $4300 / \mathrm{mm}^{3}$, and a normal CSF which proved sterile on culture. Blood cultures, however, grew Clostridium welchii and a Bacteroides, later identified as Bacteroides fragilis, after 4 days' incubation.

A gradual improvement occurred, and ventilation was stopped after 32 hours, though both liver and renal function gave concern in the next few days. A marked jaundice and hepatomegaly developed, and the serum bilirubin rose to a maximum of $35 \mathrm{mg} / 100 \mathrm{ml}$, of which $45 \%$ was conjugated, on the fifth postoperative day. The hyperbilirubinaemia and the hepatomegaly gradually subsided over the next 3 weeks.
On the second postoperative day, oliguria was noted, and the urine contained many granular casts. The blood urea rose to $154 \mathrm{mg} / 100 \mathrm{ml}$. This was attributed to acute tubular necrosis after the period of poor peripheral circulation initially. 24 hours later diuresis developed and renal function returned to normal over the next few days. On the third postoperative day, normal bowel movements occurred, and oral feeding was started.

When the results of the initial positive cultures became known, further blood cultures were drawn on the 5th, 7th, and 10th postoperative days, and all grew Bacteroides fragilis alone, though again only after several days of incubation. By this time the infant's $\mathrm{Hb}$ had fallen to $4.4 \mathrm{~g} / \mathrm{dl}$ and total white cell count had risen to $45000 / \mathrm{mm}^{3}$, with a marked neutrophil preponderance. Treatment with intramuscular erythromycin (to which the Bacteroides isolate was sensitive in vitro) was substituted for the other antibiotics, and continued for a further 10 days.

Blood transfusion raised $\mathrm{Hb}$ to $14 \mathrm{~g} / \mathrm{dl}$. The blood group determined at room temperature appeared to be $\mathrm{AB}$ and there were no antibodies in the serum. However, a previous determination of the group had shown it to be $O$ Rhesus positive, also with no antibodies in the serum, and the agglutination with anti-A, anti-B, and anti-A +B disappeared at $37^{\circ} \mathrm{C}$. Agglutination also occurred at room temperature when group $A B$ serum, known to contain no antibodies, was added to his red cells. He was given washed $O R h$ positive red cells, and the problem was later shown to be due to the presence of $T$ antigen on the patient's red cells, presumably exposed by muraminidases produced by Clostridium welchii. The baby's serum contained no anti- $T$, even 3 weeks later (anti-T develops at about the same time as anti-A and anti-B, at about 3-6 months of age), but the blood from the adult donor had contained it. The Bacteroides was not thought to be responsible for red cell damage, for all evidence of it had disappeared when the Bacteroides septicaemia recurred, and a filtrate of the organism did not induce $\mathrm{T}$ exposure in normal red cells.

After transfusion the infant's condition improved, the total white cell count returned to normal, and several further blood cultures were negative. However, three small fistulae developed at the site of the laparotomy scar. 5 days after stopping erythromycin, he again became febrile, the total white cell count rose to 18000 / $\mathrm{mm}^{3}$ and a blood culture grew Bacteroides of the same strain as before. Erythromycin was restarted, and again a good clinical response occurred. 4 days later, however, at 46 days of age and 30 days postoperatively, two convulsions occurred. CSF showed a cell count of $330 / \mathrm{mm}^{3}$, all polymorphs, a protein level of $125 \mathrm{mg} / 100$ $\mathrm{ml}$, and a glucose level of $55 \mathrm{mg} / 100 \mathrm{ml}$. Treatment was started with gentamicin intramuscularly and 
intrathecally, and sulphadiazine intramuscularly. Anticonvulsants were also given prophylactically. 2 days later CSF culture grew Bacteroides fragilis, and therapy was changed to chloramphenicol $75 \mathrm{mg} / \mathrm{kg}$ per day intramuscularly, which was continued for 15 days. A steady improvement occurred, and the abdominal fistulae healed. Two blood cultures taken after stopping chloramphenicol were negative, and the total white cell count remained normal. The main features of his illness are shown in the Fig. He was discharged well from hospital after $7 \frac{1}{2}$ weeks. Outpatient follow-up continued, and when seen at the age of 18 weeks, he was smiling, responsive, and development seemed essentially normal.

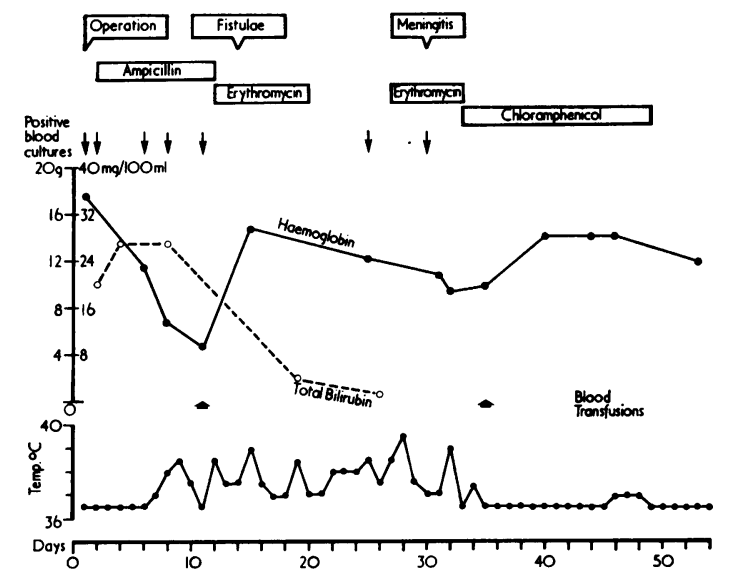

FIG.-Bacteroides fragilis septicaemia and meningitis: main features of the clinical course. Haemoglobin in g/dl; total bilirubin in $\mathrm{mg} / 100 \mathrm{ml}$.

\section{Discussion}

Bacteroides meningitis is a rare condition, and has most often been reported as a complication of chronic otitis media in both adults and children, direct spread from the middle ear being cited as the cause of the meningeal infection (Smith, McCall, and Blake, 1944; McVay and Sprunt, 1952). There are few recent reports of infection by this route, probably due to the decrease in chronic suppurative otitis media since the advent of antibiotics (Gelb and Seligman, 1970). Direct infection of the meninges by Bacteroides has also been reported after spinal surgery in an adult (Bodner, Koenig, and Goodman, 1970). More recently, cases of indirect spread of Bacteroides infections to the meninges have been described in children in whom a Bacteroides septicaemia was proven or likely to have occurred in the course of pneumonia (Flamm and Skala, 1957), pharyngitis (Tynes and Frommeyer, 1962), gastroenteritis (Lifshitz, Liu, and Thurn, 1963), and after tonsillectomy (Alston, 1955).
Improved techniques of anaerobic culture have led to an increase in the number of reports of Bacteroides septicaemia. In adults it occurs most frequently after surgery or trauma to the bowel or female pelvic organs (Bodner et al., 1970), and has also been described after upper respiratory tract infection, pneumonia, gastroenteritis, and otitis media (see review by Sanders and Stevenson, 1968).

Meningitis in this child was clearly secondary to the prolonged Bacteroides fragilis septicaemia which occurred after faecal peritonitis. The marked jaundice which developed was presumably partly due to haemolysis associated with septicaemia, and partly to a concomitant hepatitis, a recognized feature of Bacteroides infections. Though the isolate was repeatedly shown to be sensitive to erythromycin in vitro, and clinical improvement occurred during administration of this drug, septicaemia recurred shortly after it was stopped, probably as a result of incomplete eradication of loculated intra-abdominal infection, and it was during a second course of the same drug that the meningitis developed. Chloramphenicol, considered by many as the drug of choice in Bacteroides infections, was then used and achieved a clinical cure.

\section{Summary}

A case of recurrent Bacteroides fragilis septicaemia leading eventually to meningitis in a 6-week-old infant is reported. Perforation of the small bowel at the constriction ring of a strangulated inguinal hernia caused a faecal peritonitis and was the primary source of infection. Erythromycin, to which the isolate was fully sensitive in vitro, was only temporarily an effective treatment; the infection was finally eradicated with chloramphenicol, and the baby made a full recovery. Bacteroides infections in infancy and childhood are briefly reviewed.

I am grateful to Mr. P. Singh for allowing me to quote his operative findings. I should also like to thank Drs. S. M. Worlledge for giving me details of her T-antigen studies, R. S. Mitchison for the bacteriological investigations, and P. A. Davies for her encouragement in the preparation of this report.

\section{REFERENCES}

Alston, J. M. (1955). Necrobacillosis in Great Britain. British Medical fournal, 2, 1524.

Bodner, S. J., Koenig, M. G., and Goodman, J. S. (1970). Bacteremic Bacteroides infections. Annals of Internal Medicine, 73, 537.

Flamm, H., and Skala, O. (1957). Eitrige Meningitis durch Bacillus funduliformis bei einem Kind. Zentralblatt für Allgemeine Pathologie und Pathologische Anatomie, 86, 157.

Gelb, A. F., and Seligman, S. J. (1970). Bacteroidaceae bacteremia: effect of age and focus of infection upon clinical course. fournal of the American Medical Association, 212, 1038. 
Lifshitz, F., Liu, C., and Thurn, A. N. (1963). Case reportBacteroides meningitis. American fournal of Diseases of Children, 105, 487.

McVay, L. V., and Sprunt, D. H. (1952). Bacteroides infections. Annals of Internal Medicine, 36, 56

Sanders, D. Y., and Stevenson, J. (1968). Bacteroides infections in children. Fournal of Pediatrics, 72, 673.

Smith, W. E., McCall, R. E., and Blake, T. J. (1944). Bacteroides infections of the central nervous system. Annals of Internal Medicine, 20, 920.

Tynes, B. S., and Frommeyer, W. B. (1962). Bacteroides septicaemia. Annals of Internal Medicine, 56, 12.

RICHARD W. I. CoOKE*

Department of Paediatrics and Neonatal Medicine, Hammersmith Hospital, Du Cane Road, London W12 0HS.

*The Hospital for Sick Children, Great Ormond St., London WC1N 3JH.

\section{Bile acid excretion after pull-through operation for Hirschsprung's disease}

Patients who have undergone a 'pull-through' operation for Hirschsprung's disease may suffer from chronic diarrhoea and excoriation of the perianal skin which can persist for months, sometimes years (Ehrenpreis, 1971). The cause of these symptoms has not been fully elucidated and no effective form of therapy has been devised.

As part of a study of these problems the possibility that altered bile acid metabolism might play a role in altering intestinal function and producing diarrhoea was considered. We report the results of an investigation of faecal and duodenal bile acids in four such patients.

\section{Materials and methods}

Four patients who had persistent diarrhoea and perianal excoriation after a Soave pull-through operation (1964) and one patient (Case 5) with a colostomy for Hirschsprung's disease were studied (Table I).

Duodenal contents were aspirated fasting and after intravenous pancreozymin ${ }^{\star}(1$ Ivy Dog unit $/ \mathrm{kg}$ body

$\star$ Karolinska Institute, Stockholm. weight). Bile acid concentrations in the aspirates and also in three 24-hour collections of faeces were determined using $3 \alpha$-hydroxysteroid dehydrogenase and fluorimetry (Murphy, Billing, and Baron, 1970). Individual bile acids were estimated by combining this technique with thin-layer chromatography and $7 \alpha$-hydroxysteroid dehydrogenase (Haslewood, Murphy, and Richardson, 1973). Faecal fat excretion was determined on the same faecal specimens that were used for bile acid determination. Samples of fasting gastric and duodenal fluid were examined bacteriologically using the procedures of Drasar, Shiner, and McLeod (1969).

\section{Results}

The results of faecal fat and faecal and duodenal bile acid determinations are given in Table II. Faecal bile acids were raised in all 4 children who had undergone the Soave operation, when compared to values found in Case 5, and in 10 control children aged between 1 and 7 years.

It was not considered ethical to intubate normal children merely to provide control data for this study and the results of duodenal bile acid analyses in the 5 patients have been compared to 'normal values' taken from published reports. All 5 patients achieved duodenal bile acid concentrations after pancreozymin stimulation which were within the normal range (Weber and Roy, 1972), thus indicating that the bile acid losses via faecal excretion did not exceed the ability of the liver to replenish the bile salt pool.

Cases 2 and 3, who had the highest faecal bile acid levels, also had the highest values for the ratio of glycine conjugated bile acids to taurine conjugated bile acids ( $\mathrm{G} / \mathrm{T}$ ratio) in the duodenal aspirate. In this regard it must be noted that all the children studied were more than one year old and consequently would be expected to have $G / T$ ratio values within the normal adult range (Murphy and Signer, 1974).

In Case 2 an abnormally high proportion of cholic acid was found in the duodenal aspirate after pancreozymin stimulation. Further analysis indicated that conjugated deoxycholic acid (a

TABLE I

Patients studied

\begin{tabular}{|c|c|c|c|c|}
\hline Case no. & $\begin{array}{c}\text { Age at } \\
\text { operation }(m)\end{array}$ & $\begin{array}{l}\text { Age at time } \\
\text { of study } \\
\text { (yr) (m) }\end{array}$ & Diarrhoea & $\begin{array}{l}\text { Anal } \\
\text { excoriation }\end{array}$ \\
\hline $\begin{array}{l}1 \\
2 \\
3 \\
4 \\
5\end{array}$ & $\begin{array}{c}11 \\
13 \\
13 \\
3 \cdot 4 \text { yr } \\
12\end{array}$ & $\begin{array}{rr}2 & 11 \\
3 & 7 \\
2 & 7 \\
6 & 6 \\
1 & 1\end{array}$ & $\begin{array}{l}\text { Severe } \\
\text { Severe } \\
\text { Moderate } \\
\text { Moderate } \\
\text { Absent }\end{array}$ & $\begin{array}{c}\text { Severe } \\
\text { Severe } \\
\text { Mild } \\
\text { Moderate }\end{array}$ \\
\hline
\end{tabular}

